\title{
Only Human: Mental-Health Difficulties Among Clinical, Counseling, and School Psychology Faculty and Trainees
}

\author{
Sarah E. Victor ${ }^{1}$, Andrew R. Devendorf ${ }^{2}$, Stephen P. Lewis ${ }^{3}$, Jonathan Rottenberg ${ }^{2}$, \\ Jennifer J. Muehlenkamp ${ }^{4}$, Dese'Rae L. Stage ${ }^{5}$, and Rose H. Miller ${ }^{2}$ \\ ${ }^{1}$ Department of Psychological Sciences, Texas Tech University; ${ }^{2}$ Department of Psychology, \\ University of South Florida; ${ }^{3}$ Department of Psychology, University of Guelph; ${ }^{4}$ Department of \\ Psychology, University of Wisconsin-Eau Claire; and ${ }^{5}$ School of Social Work, Temple \\ University
}

Corresponding Author: Sarah E. Victor, Department of Psychological Sciences, Texas Tech University Email: sarah.victor@ttu.edu

This work has been accepted for publication at Perspectives on Psychological Science. It was first published online on June 22, 2022. Copyright $\mathbb{C}$ Association for Psychological Science. The version of record is available here: $\mathrm{https}$ ://doi.org/10.1177/17456916211071079 


\begin{abstract}
How common are mental-health difficulties among applied psychologists? This question is paradoxically neglected, perhaps because disclosure and discussion of these experiences remain taboo within the field. This study documented high rates of mental-health difficulties (both diagnosed and undiagnosed) among faculty, graduate students, and others affiliated with accredited doctoral and internship programs in clinical, counseling, and school psychology. More than $80 \%$ of respondents $(n=1,395$ of 1,692$)$ reported a lifetime history mental-health difficulties, and nearly half (48\%) reported a diagnosed mental disorder. Among those with diagnosed and undiagnosed mental-health difficulties, the most common reported concerns were depression, generalized anxiety disorder, and suicidal thoughts or behaviors. Participants who reported diagnosed mental disorders endorsed, on average, more specific mental-health difficulties and were more likely to report current difficulties than were undiagnosed participants. Graduate students were more likely to endorse both diagnosed and undiagnosed mental-health difficulties than were faculty, and they were more likely to report ongoing difficulties. Overall, rates of mental disorders within clinical, counseling, and school psychology faculty and trainees were similar to or greater than those observed in the general population. We discuss the implications of these results and suggest specific directions for future research on this heretofore neglected topic.
\end{abstract}

\title{
Keywords
}

clinical psychology, mental health, psychopathology, mental illness, prevalence 
People working in applied ${ }^{1}$ fields of psychological science (such as clinical, counseling, and school psychology) strive to understand and alleviate suffering due to mental disorders (Kazdin \& Blase, 2011). Psychologists have played instrumental roles in documenting the ubiquitous nature of mental disorders across sociocultural groups (Chou et al., 2012), developmental periods (Caspi et al., 2020), and professions (Campbell et al., 2018). Indeed, nationally representative data suggest that anywhere from $33 \%$ to $86 \%$ of people will experience mental disorders in their lifetimes (Caspi et al., 2020; Kessler et al., 2005; Statistics Canada, 2014). Yet this article is motivated by a peculiar gap: Remarkably little is known about the prevalence of mental-health difficulties among faculty or trainees within applied clinical psychological science. In this article, we discuss why this gap is both paradoxical and harmful. Logically, achieving the mission of applied psychology requires extending its knowledge and paradigms to those within the field.

The striking absence of research on the prevalence of mental-health difficulties within the field of clinical psychological science is particularly notable with respect to faculty, for which there are virtually no data. It is unlikely that applied psychologists are inoculated from the phenomena that they study and treat. Although educational attainment has been negatively associated with mental disorders in the general population (Breslau et al., 2008), surveys of graduate students indicate elevated rates of current mental disorders (Evans et al., 2018). For example, a national survey of U.S. graduate students found that more than a quarter met criteria for a current or recent mental-health difficulty (Lipson et al., 2016). Among Canadian psychology graduate students, one third reported current clinically significant symptoms of depression (Peluso et al., 2011). Furthermore, data from a large Belgian study suggest that rates of mental disorders appear to be significantly greater among graduate students than among other 
highly educated community members (Levecque et al., 2017). However, data specific to the prevalence of mental-health difficulties among trainees and faculty within clinical, counseling, and school psychology are missing.

The lack of attention to mental-health difficulties within these fields stands out, given that people working in clinical, counseling, and school psychology engage in self-study and reflection in other domains. For example, ample research has been conducted by applied psychologists with respect to training health professionals (Benuto et al., 2018) and conducting scientific research (Royalty \& Reising, 1986). Applied psychologists regularly emphasize the importance of improving the field from within, for instance, with respect to replicability (Asendorpf et al., 2013); open science (Washburn et al., 2018); and diversity, equity, and inclusion (Neblett, 2019). Inattention to mental-health difficulties within the field is also potentially hypocritical, given that applied psychologists have been known to examine the prevalence of mental disorders in other professions, such as policing (Angehrn et al., 2021) and the military (Campbell et al., 2018), and make impassioned arguments for decreasing stigma toward mental disorders (Maranzan, 2016). These outreach activities render the lack of research on mental disorders and difficulties within the professions of applied psychology all the more perplexing.

This lack of self-study may also curtail the personal and/or professional development of those within these disciplines. Evidence suggests that faculty with mental disorders struggle to obtain necessary accommodations and professional supports (Price et al., 2017). Although data on psychology trainees are lacking, mental-health accommodations and supports are likely to be even more important at earlier stages of one's career, when students may face additional barriers to accessing care, and may have more limited financial and support resources, which may make 
coping with mental disorders more difficult. Further, lived experience of mental disorders within the psychology workforce is typically not included in discussions of diversifying psychological science (Stewart et al., 2017). In this sense, the omission of consideration of lived experiences of mental disorders among psychologists may end up perpetuating the very stigma that applied psychology purports to combat. This omission stands in stark contrast to broader conversations about the need to improve inclusive practices to support people from diverse backgrounds within our fields (Neblett, 2019). Lack of consideration of the ways in which people with mental-health difficulties may be excluded parallel the ways in which people with disabilities have also been marginalized in psychological science, including with respect to efforts to enhance diversity (Andrews \& Lund, 2015). These consequences underscore why we urgently need research examining mental-health difficulties within the profession of applied psychological science.

\section{Prior Research on Mental Health Among Psychology Students and Faculty}

Most research on professional experiences with mental-health difficulties examines experiences with psychotherapy and/or factors that influence willingness to seek psychological help. Although this work suggests that mental-health difficulties may be prevalent among practitioners, it does not directly address the prevalence of such experiences within trainees and/or research psychologists in the field. In two U.S. studies with relatively small samples $(N \mathrm{~s}<$ $300)$, rates of psychotherapy utilization were high among practicing psychologists ( $86 \%$; Bearse et al., 2013) and psychology trainees (70\%; Dearing et al., 2005) compared with the general population (Gonzalez et al., 2013). Unfortunately, few data were obtained on the types of mental-health difficulties (if any) that led to therapy attendance. Likewise, in a U.S. sample of practicing counseling psychologists $(N=425), 60 \%$ reported major depression, but other types of mental disorders were not assessed (Gilroy et al., 2002). In perhaps the largest survey of 
American psychologists' experiences with psychotherapy, conducted more than 25 years ago $(N$ $=476 ;$ Pope $\&$ Tabachnick, 1994), 84\% of respondents reported having attended therapy as a client, most commonly for self-reported depression. In research from the United Kingdom, 63\% of registered psychologists and $67 \%$ of psychology trainees reported lifetime histories of mental difficulties (Grice et al., 2018; Tay et al., 2018). These studies provide preliminary evidence that mental-health difficulties are prevalent within the profession of psychology, at least with respect to practitioners. Many such studies have narrowly focused on the possibility of professional impairment (e.g., Smith \& Moss, 2009; Thoreson \& Miller, 1989), which is clearly worthy of consideration, but data from this context may have little bearing on whether individuals with mental disorders who pursue research careers can succeed.

As noted previously, there is a tension in the field between public-facing efforts to reduce and combat stigma toward mental disorders and the limited efforts to address this stigma within the profession. Although mental-health professionals, on average, endorse less stigmatizing views of people with mental disorders than the general public, they still commonly report negative views overall (Wahl \& Aroesty-Cohen, 2010). American clinical psychologists, for instance, rate people with mental disorders as more ineffective, incomprehensible, dangerous, unworthy, and undesirable than they rate themselves (Servais \& Saunders, 2007). A classic and oft-cited article described disclosure of an applicant's mental-health difficulties as a "kiss of death" in psychology graduate school admissions (Appleby \& Appleby, 2006); the advice to avoid disclosure of mental disorders is now commonly repeated in graduate-school admissions guides (Devendorf, 2022). This and other well-intentioned advice likely causes harm by perpetuating stigma and suggesting the unacceptability of lived experience within academic and professional psychology. This messaging may even decrease willingness among trainees to seek 
help from professional mentors following graduate school admission. For example, a survey of British trainee psychologists with mental-health difficulties found that odds of disclosure were lowest for supervisors and instructors compared with family, friends, and health professionals (Grice et al., 2018). Furthermore, a recent study on the psychology faculty hiring process did not explicitly assess mental disorders but identified "exhibiting difficult personality traits" as the most strongly endorsed "kiss of death," highlighting how interpersonal perceptions continue to play a critical role even at the level of faculty selection procedures (Boysen et al., 2019). Anecdotal data highlight the urgency of systematically examining disclosure of mental-health difficulties in academic settings, including whether disclosures may be disincentivized as a result of fears of negative professional consequences, such as failure to obtain funding, promotions, and/or admission to graduate school (Devendorf, 2022; Joseph et al., 2022; Vierthaler \& Elliot, 2020).

Given the limited nature of prior work, and the need for systematic, empirical investigation, we developed a cross-sectional study designed to estimate the prevalence of reported diagnosed and undiagnosed mental-health difficulties among applied-psychology faculty and trainees in the United States and Canada. We focused specifically on clinical, counseling, and school psychology doctoral programs and internships because these fields inform the public's wider perceptions of psychology and are accredited by major national bodies, allowing us to obtain complete information on eligible programs and to gather contact information from program affiliates in a replicable and comprehensive way.

Our primary goal was to provide estimates of prevalence and correlates of reported formally diagnosed and undiagnosed mental-health difficulties among psychology graduate students and faculty. Indeed, one key strength of this project was the ability to differentiate 
between individuals who reported mental-health difficulties, broadly defined, and those who had been diagnosed with a mental disorder by a professional. To our knowledge, prior survey research in this area has exclusively relied on self-reported mental-health difficulties, without asking about formal diagnoses (Gilroy et al., 2002; Grice et al., 2018; Pope \& Tabachnick, 1994; Tay et al., 2018). This approach has several benefits, given that a large proportion of people with diagnosable mental disorders do not receive treatment or a formal diagnosis (Wang et al., 2005). This may be particularly true for people who experience barriers to help-seeking, such as psychologists and trainees (Elliott \& Ragsdale, 2020; Tay et al., 2018), and members of minoritized groups, who often face additional obstacles to mental-health care and whose experiences may not be adequately conceptualized in diagnostic classification systems (Cook et al., 2017; Gray-Little, 2009). In addition, some clinically significant mental-health difficulties are not presently categorized as mental disorders (e.g., nonsuicidal self-injury, suicidal thoughts and behaviors), and thus may be missed by sole reliance on diagnostic history, as would subthreshold mental-health difficulties, which are often clinically significant and impairing (Forsell, 2007; Kotov et al., 2017). However, reliance on self-report can muddle consideration of whether described mental-health difficulties necessarily meet diagnostic thresholds for clinical severity and impairment, and therefore a stricter approach, relying on receipt of diagnosis from a professional, may provide uniquely valuable information. Thus, we gathered data on diagnosed and undiagnosed mental-health difficulties in this sample, to facilitate comparisons between those with and without diagnoses on correlates, clinical features, and professional problems.

Although experiences of mental-health difficulties are likely to be nuanced, variable, and influenced by key contextual factors, our primary aim herein was to obtain representative data on these experiences broadly, which may then inform future studies using more intensive data- 
collection methods to dive deeper into questions that do not lend themselves to self-report survey methodologies (e.g., temporal ordering of experiences relative to professional development, specific diagnoses as they relate to domains of professional problems, operationalization of recovery and remission from mental disorders). As the first comprehensive data collection in this area, our investigation was preregistered with the goal of characterizing the sample rather than testing specific hypotheses. The larger survey from which these data are derived included several other topics that, for reasons of space, are not reported here.

\section{Method}

\section{Study methodology, recruitment, and sampling}

Contact information (i.e., email addresses) was collected for faculty, graduate students, and postdoctoral trainees affiliated with accredited U.S. and Canadian doctoral training programs in clinical, counseling, and school psychology, as well as for directors of clinical training (DCTs) at accredited doctoral internship programs in the United States and Canada. A recruitment email was sent on January 24, 2021, and a reminder email was sent on February 1, 2021. The survey remained open until March 1, 2021. Participants were eligible to enter a drawing for one of several \$50 Amazon gift cards (U.S. or Canadian dollars, as applicable), which were awarded at a ratio of 1 per 100 participants or fraction thereof. Ultimately, 21 Amazon gift cards were distributed in the 2 weeks following survey closure. All study procedures were approved by, and conducted in accordance with, the principal investigator's institutional review board (IRB) at Texas Tech University. The study design and methodology were preregistered at OSF

\section{(https://osf.io/vtxa2/).}

Diligent efforts were made to ensure representative sampling and recruitment. First, a comprehensive list of websites of doctoral programs accredited by the American Psychological 
Association (APA), the Canadian Psychological Association (CPA), or the Psychological Clinical Science Accreditation System was obtained from web repositories in summer 2020. If a web link was outdated or did not work, a web search was initiated to find the current website for each program. Then, trained research assistants obtained publicly available email addresses for faculty (including DCTs), graduate students, and postdoctoral scholars affiliated with each accredited program. Research assistants were trained using standardized video training materials developed by S. E. Victor, and a subset of data were double entered by a graduate student to ensure accuracy. Research assistants were advised to err on the side of overinclusion, such that listed email addresses for adjunct faculty, clinical affiliates, and retired faculty were included if available. A comprehensive list of doctoral internships that are members of the Association of Psychology Postdoctoral and Internship Centers (APPIC) was simultaneously obtained from the APPIC internship directory. Because internship websites provide far less accessible contact information (on average) than departmental websites, we chose to limit contacts for internship programs to the DCTs whose emails were listed in the APPIC directory. For emails to which messages were undeliverable, addresses were inspected manually, corrected if erroneous, and otherwise retried at least twice. Emails that were invalid at both attempts were removed from the total count of distributed emails; thus, the number of emails sent reflects emails actually delivered. If an individual responded to state that they were not affiliated with an accredited program, the email was removed from the contact list, and no reminder was sent.

A set of advertising emails were developed that varied on the basis of what information was publicly available on a program's website. For instance, if a program listed email addresses for faculty but not students, emails sent to faculty explicitly asked them to forward the email to students. In advertisements and the consent form, the study was described as focusing on 
"research and clinical interests," and there was no mention of personal mental-health conditions. Emails were distributed as being "from" S. E. Victor, unless there was a potential conflict of interest, in which case they were sent as "from" another member of the research team. The exact text of study advertisements is available at https://osf.io/vtxa2/.

\section{Survey instrument}

Most survey items were developed specifically for this project in consultation with coauthors and reviews of prior literature. The overall goals of the survey were threefold: (a) Characterize prevalence and characteristics of undiagnosed mental-health difficulties and diagnosed mental disorders among psychology faculty and trainees; (b) characterize prevalence and characteristics of research on personally relevant topics (self-relevant research); and (c) examine perceptions of the acceptability of self-relevant research using experimentally manipulated vignettes. The current study focuses only on the first aim. To address the first goal, we asked participants to respond (in addition to providing demographic characteristics) to two yes/no items assessing experiences of mental-health diagnosis ("Have you ever been diagnosed with a mental health condition by a professional?") and mental-health difficulties ("Have you ever experienced mental health difficulties?"). The terminology used for this second question was intentionally broad, consistent with prior work (e.g., Grice et al., 2018; Tay et al., 2018), to allow for examination of differences between individuals with self-reported mental-health difficulties only and people with formally diagnosed mental disorders (see above for further rationale). For participants who endorsed either or both of these items, follow-up items were provided to assess onset, offset (recency), perceived professional problems, and type of difficulty experienced. 
The survey was distributed via Qualtrics and took 15 to $30 \mathrm{~min}$ on average to complete. Beyond the consent form, all survey items could be skipped. Participants who wished to enter the drawing for an Amazon gift card were directed to a separate survey to provide their contact information, and those responses could not be tied to actual survey responses. After data collection, quantitative and qualitative data were separated, per IRB guidelines, to avoid accidental reidentification of respondents.

\section{Data analytic plan}

Descriptive analyses ( $n$ and percentage, means and standard deviations) were used to characterize the sample and prevalence of mental-health difficulties and diagnoses. Second, we planned to compare variables of interest across relevant groups for those with cell sizes of five or greater. Potential group comparisons were examined on the basis of the following characteristics: gender, race/ ethnicity, age, professional status (e.g., faculty, graduate student), accrediting body (e.g., APA, CPA), training model (e.g., scientist-practitioner, practitioner-scholar), program type (e.g., $\mathrm{PhD}$, PsyD), and professional areas of study (e.g., clinical, counseling, school). Group comparisons for dichotomous variables were conducted using $\chi 2$ tests, whereas comparisons for dimensional variables were conducted using independent-samples $t$ tests or one-way analyses of variance (ANOVAs).

\section{Results}

Survey distribution and sample size

A total of 8,952 emails were distributed (delivered) across accredited doctoral training programs and internships. In the case of training programs $(N=433)$, emails were sent to 432 DCTs (the remaining DCT being a coinvestigator), 4,791 faculty, 2,949 students, and 100 postdoctoral trainees. Programs were primarily APA-accredited $(n=395)$, offered training in 
clinical psychology $(n=270)$, were located in the United States $(n=395)$, and offered a $\mathrm{PhD}$ degree $(n=339)$. In the case of internships $(N=680)$, emails were available for all but two programs, the majority of which were APA-accredited $(n=642)$.

A total of 2,045 people consented to participate $(22.8 \%$ of emails distributed, a response rate similar to that from prior work; Tay et al., 2018). Forty-two responses were removed because the participant was pursuing a Bachelor's degree $(n=3)$, was in a nonaccredited program $(n=9)$, or program accreditation was marked as "not relevant" $(n=30)$. An additional 44 responses were removed because no items were completed beyond the consent form. This left an analytic sample of 1,959 .

\section{Sample characteristics}

Respondents were primarily graduate students $(59.83 \%)$ or faculty $(27.62 \%)$; smaller percentages of respondents indicated their primary professional status as clinician $(7.76 \%)$, postdoctoral trainee $(3.06 \%)$, or other $(1.68 \%)$. Responses were primarily from affiliates of APA-accredited programs $(87.02 \%)$ and programs that grant $\mathrm{PhD}$ degrees $(71.84 \%)$, which was similar to the distribution of delivered emails $(\mathrm{APA}=88.93 \% ; \mathrm{PhD}=79.71 \%)$. Detailed characteristics of respondents' professional statuses and affiliations are available in Table S1 in the Supplemental Material available online.

Participants were primarily cisgender women (77.94\%) or cisgender men (20.16\%); mean participant age was 34.2 years $(S D=11.7)$. Most participants were non-Hispanic/Latinx White (75.94\%) and heterosexual/straight (78.82\%). Relative to graduate students, faculty were, on average, older, $t(565.6)=35.1, p<.001$, and more likely to be cisgender men, nonHispanic/Latinx White, and heterosexual/straight. The sample overall included a higher percentage of cisgender women and non-Hispanic/Latinx White individuals than the population 
of graduate students and faculty in U.S. clinical, counseling, and school-psychology programs (Page et al., 2017). Additional demographic characteristics and comparisons are provided in Table S2 in the Supplemental Material.

\section{Mental health characteristics}

The overwhelming majority of respondents $(n=1,395 ; 82.20 \%)$ reported experiencing a mental-health difficulty, and almost half $(n=803 ; 47.53 \%)$ of respondents reported having been formally diagnosed with a mental-health condition. Participants were thus divided into three groups: no mental-health difficulties or diagnoses $(n=295 ; 17.51 \%)$, mental-health difficulties without a diagnosis $(n=587 ; 34.84 \%)$, or reported mental-health diagnoses $(n=803 ; 47.66 \%)$. When referring to the broad group of respondents who report mental-health difficulties with or without diagnoses, we use the term "mental-health difficulties"; when we refer specifically to participants who report mental-health difficulties without a formally diagnosed mental disorder, we use the term "undiagnosed."

Among all participants with mental-health difficulties, reported onset was most common before graduate training (83.07\%), and a majority reported past (rather than current) difficulties (55.85\%). Professional problems related to mental-health difficulties were reported by just over half of these participants (51.48\%) and were typically mild (78.48\%). Onset before graduate school, current (versus past) difficulties, and professional problems were significantly more common for diagnosed participants relative to participants with undiagnosed mental-health difficulties. Among participants who reported professional problems, those with and without diagnoses did not differ in the domains of problems reported (see Table 1 for further results).

Participants with both diagnosed and undiagnosed mental-health difficulties reported an average of 3.3 specific mental-health difficulties in their lifetimes $(S D=2.2)$ and 1.1 currently 
$(S D=1.3)$; formally diagnosed participants reported higher numbers of lifetime difficulties, $t(1372.63)=14.91, p<.001$, and current difficulties, $t(1366.39)=11.08, p<.001$, than participants with undiagnosed mental-health difficulties. Depression, generalized anxiety disorder, and suicidal thoughts or behaviors were the three most common difficulties for both participants with undiagnosed mental-health difficulties and diagnosed mental disorders. In examining rates of specific difficulties, we controlled for total number of difficulties and used an adjusted $p$-value threshold of .01 because of multiple comparisons. Analyses indicated that rates of depression, generalized anxiety disorder, and attention-deficit/hyperactivity disorder were higher among participants with diagnosed mental disorders relative to participants with undiagnosed mental-health difficulties. Furthermore, rates of social anxiety disorder, specific phobia, and "other" conditions were lower than expected among participants with diagnosed mental disorders relative to participants with undiagnosed mental-health difficulties (see Table S3 in the Supplemental Material).

\section{Group comparisons}

There were significant differences between the groups with respect to demographic characteristics (see Table 2). Consistent with extant data on gender differences in mental illness (Kessler, 2004), cisgender women were more likely than cisgender men to have a mentaldisorder diagnosis and less likely to have no reported mental-health difficulties. This was also the case for bisexual and homosexual participants relative to heterosexual/straight participants. A one-way ANOVA predicting age demonstrated significant group differences, $F(2,1656)=45.73$, $p<.001$, such that participants with no mental-health difficulties were, on average, older than participants with both diagnosed mental disorders and undiagnosed mental-health difficulties. Hispanic/Latinx participants were overrepresented compared with biracial, multiracial, or 
“other"-identified participants among participants with no mental-health difficulties; among participants with a diagnosed mental disorder, non-Hispanic/Latinx White participants were overrepresented relative to participants of Asian descent.

There was no significant relation between group and program type or area of study (see Table 3). Respondents from APA-accredited programs were overrepresented among participants with diagnosed mental disorders and underrepresented in the undiagnosed mental-health difficulties group relative to respondents from CPA-accredited programs. Group status was significantly associated with program training type, which was driven by differences in rates of diagnosed mental disorders across programs; participants from clinical-science programs were overrepresented in this category relative to participants from scientist-practitioner programs.

There were significant group differences based on professional status (faculty, postdoc, graduate student, clinician, other; see Table 3). Graduate students were underrepresented among participants with no mental-health difficulties relative to all professional groups and overrepresented among participants with diagnosed mental disorders relative to faculty. In addition, postdocs were underrepresented among participants with no mental-health difficulties relative to faculty and "other" respondents. On the basis of the above results, and the comparatively small samples of clinicians, postdocs, and "other" professionals, we focused the remainder of the analyses on comparisons between faculty and graduate students $(87.49 \%$ of the full sample).

\section{Group comparisons of faculty and graduate students}

Compared with faculty, graduate students were overrepresented among participants with undiagnosed mental-health difficulties (students $=36.53 \%$; faculty $=30.31 \%$ ) and diagnosed mental disorders (students $=52.33 \%$; faculty $=40.49 \%$ ) and underrepresented among those with 
no mental-health difficulties ( students $=11.14 \%$; faculty $=29.20 \%$ ). Among participants with any mental-health difficulties (diagnosed or undiagnosed), graduate students were more likely to report onset before graduate school, relative to during graduate school, compared with faculty, which may be an artifact of the reality that current students have spent fewer years in graduate training (being currently enrolled) compared with faculty (who have completed graduate training). Among faculty and graduate students with undiagnosed or diagnosed mental-health difficulties, graduate students were also more likely to report current mental-health difficulties and less likely to report offset of mental-health difficulties more than 5 years ago than were faculty (see Table 4). On average, graduate students also reported more specific lifetime mentalhealth difficulties, $t(644.48)=6.44, p<.001$, and current mental-health difficulties, $t(693.32)=$ $8.30, p<.001$, than faculty.

Faculty were more likely than graduate students to report that their mental-health difficulties caused no, or mild, professional problems. Graduate students were more likely to report problems with coursework, which may be more salient or easily recalled for graduate students, whose enrollments are much more recent. Faculty were more likely to report problems with teaching and in "other" domains, which may be attributable to the greater expectations in these areas among faculty relative to graduate students. There were no faculty/ student differences in perceived problems in other domains (see Table 4).

Given possible differences across participants with undiagnosed versus diagnosed mental-health difficulties, we subsequently reanalyzed the above comparisons in each group separately, which yielded an overall consistent pattern of findings. For example, among those with undiagnosed mental-health difficulties, graduate students reported significantly more lifetime and current mental-health difficulties than did faculty—lifetime, $t(275.79)=2.66, p=$ 
.008 ; current: $t(433.30)=7.89, p<.001$ —and this was also true for participants with diagnosed mental disorders_-lifetime: $t(346.37)=5.96, p<.001$; current $t(344.19)=5.55, p<.001$. In some cases, statistically significant results fell below the threshold of $p<.05$ in subgroup analyses, which is likely to be due to decreased statistical power as a result of smaller sample sizes. Full results are provided in Table S4 in the Supplemental Material.

Because graduate students reported more lifetime mental-health difficulties than did faculty, comparisons of prevalence of specific mental-health difficulties were conducted with partial $\phi$ coefficients and by controlling for total lifetime mental-health difficulties using an adjusted $p$ value of .01 for multiple comparisons (see Table 5 in the Supplemental Material). Generalized anxiety disorder was more common than expected among graduate students, whereas substance use disorder and specific learning disorder were more common than expected among faculty.

\section{Discussion}

Clinical, counseling, and school psychologists have long failed to conduct rigorous assessment of their own mental-health experiences. This neglect may be driven (somewhat ironically) by explicit recommendations that psychologists should avoid disclosing experiences of mental-health difficulties (e.g., Appleby \& Appleby, 2006), given that disclosures may be viewed as "unprofessional" or "inappropriate" (Devendorf, 2022). In addition, there are perceptions that lived experience can "bias the objectivity" of a psychologist (Victor et al., 2022), which may motivate individuals to hide their experiences and to disincentivize psychological scientists from scrutinizing the experiences of our own profession as we do others (e.g., Angehrn et al., 2021; Campbell et al., 2018). Limiting such open discussions has seemingly created the notion that psychologists do not—or ought not to-experience mental-health 
difficulties, which runs contrary to explicitly stated efforts to improve the field's inclusive principles and practices to foster more diverse psychological sciences (Neblett, 2019).

These data, drawn from nearly 2,000 trainees and faculty, provide strong evidence that mental-health difficulties are at least as prevalent in the fields of applied psychology as in other professions. We found that $82 \%$ of respondents reported lifetime mental-health difficulties, and almost half reported formal diagnosis of one or more mental disorders. The lifetime prevalence rates that we observed in our sample of faculty and trainees are comparable to or greater than those observed in the general population; data from rigorous longitudinal research demonstrate that $46 \%$ to $86 \%$ of people meet diagnostic criteria for a lifetime mental disorder (Caspi et al., 2020; Kessler et al., 2005). Put simply, applied psychologists are not immune to mental-health difficulties.

It is noteworthy that American/Canadian graduate students in this sample reported nominally higher prevalence rates of mental-health difficulties (88.5\%) compared with U.K. trainees (67\%; Grice et al., 2018) and American/Canadian faculty exhibited nominally higher prevalence of mental-health difficulties (70.5\%) compared with what prior research has found for clinical psychologists registered in the United Kingdom (63\%; Tay et al., 2018). However, across these samples, the overall distribution of specific difficulties was similar; depression and anxiety were most common, and bipolar and psychotic disorders were among the least common (Tay et al., 2018). We found that nonsuicidal self-injury and suicidal thoughts/behaviors, although not formal diagnoses, were quite prevalent in this sample, highlighting the importance of understanding these phenomena among applied psychology faculty and trainees. Further, these data expand upon prior work by allowing comparisons between individuals with formally diagnosed and undiagnosed mental-health difficulties, whereas almost no prior self-report 
research has examined explicitly whether reported mental-health difficulties were diagnosed by a professional.

The most reported specific mental-health difficulty in this sample, depression, was endorsed by over half of participants in the full sample, including respondents with no reported mental-health difficulties at all. This prevalence rate is notably higher than lifetime U.S. population prevalence estimates of major depressive disorder derived from clinical interviews (21\%; Hasin et al., 2018). Because our use of the term "mental-health difficulties" was intentionally broad, our depression finding lends itself to several possible interpretations. This may reflect improved accuracy in identifying mental-health difficulties such as depression by psychology faculty and graduate students relative to the general population, as our respondents are both trained to diagnose mental disorders and may encounter them more regularly in their professional work than individuals in other fields. Alternatively, it may reflect a reporting bias such that applied psychologists view "subthreshold" depression as noteworthy, given knowledge of the limitations of extant diagnostic frameworks. Finally, there may be substantive interpretations. For example, experiences within applied psychology training and professional settings may contribute to depression, although the vast majority (over $80 \%$ ) of respondents reported onset of mental-health difficulties before graduate training, so this possibility is not strongly supported by our data. Alternatively, people with mental-health difficulties, such as depression, may be more likely to self-select into applied-psychology training relative to the general population, although further research is needed to investigate this question.

Despite high rates of mental-health difficulties, more than $95 \%$ of participants with undiagnosed mental-health difficulties and more than $80 \%$ of those with diagnosed mental disorders reported "no" or "mild" professional problems related to these experiences; those 
reporting problems were most likely to have experienced these in research and/or coursework. To our knowledge, there has been no prior study of professional problems among psychologists across multiple domains. These results contrast with earlier research, in which more than $60 \%$ of surveyed U.S. psychologists reported "working when too distressed to be effective," even though $47 \%$ of respondents in the same survey felt doing so was "unquestionably not ethical" (Pope et al., 1987) perhaps because distress that causes work difficulties is not always the result of a mental-health difficulty or disorder. It is noteworthy that our findings suggest that mental-health difficulties do not invariably or always prevent psychologists from being effective at work. That said, one limitation of our study is that we did not assess problems in other important domains of functioning, such as interpersonal relationships; thus, it is possible that mental-health difficulties among psychologists cause more significant problems outside of work contexts.

Overall, the significant rates of both diagnosed and undiagnosed mental-health difficulties among psychologists warrant a call to accept, advocate for, and ultimately incorporate these lived experiences in discussions about diversity and inclusivity within clinical psychology. Just as psychologists are (rightly) advocating for increased racial, ethnic, gender, and sexual orientation diversity within our ranks (Gruber et al., 2020; Henrich et al., 2010), so too should psychologists be concerned about inclusion of people with lived experience of mental-health difficulties as a matter of equity and justice. Leaders in disability advocacy have long argued "nothing about us without us" (Charlton, 1998), and yet psychologists have failed to consider how the exclusion of people who have experienced mental disorders may harm not only the professional and educational goals of those individuals but also the progress of mental-health research as a whole (Jones et al., 2021). Psychological science benefits from the inclusion of both scholars and practitioners with varied experiences and identities, which not only fosters 
diversity of thought and inquiry but also ensures that the application of our work is inclusive and equitable. Given that clinical, counseling, and school psychology in particular explicitly seek to understand and support people with mental-health difficulties, further discussion of this data set — the strongest evidence to date that mental-health difficulties are fairly widespread among applied psychologists - could be an important catalyst for a needed conversation that allows the field of applied psychology to better fulfill its mission.

In our study, graduate students, compared with faculty, were more likely to report both diagnosed and undiagnosed mental-health difficulties and to show markers of higher severity, including earlier onset, greater number of difficulties, and higher likelihood of professional problems associated with these experiences. There may be several reasons for these results. First, there are significant time and cohort effects with respect to mental-disorder prevalence (Twenge et al., 2019) and willingness to seek diagnosis and treatment (Chiu et al., 2020). Second, because graduate students are younger and thus closer to the typical age of onset for many mental disorders, less time has elapsed for symptoms to remit, thus making mental-health difficulties more salient; the fact that current (vs. past) prevalence rates were also higher among graduate student respondents is consistent with this hypothesis. Further, acute stressors associated with doctoral training, such as limited financial resources, moving away from family and friends, and job insecurity, may exacerbate mental-health difficulties in graduate trainees (Eleftheriades et al., 2020; Hyun et al., 2006), and/or faculty may have developed effective coping strategies to curb the impact of mental-health difficulties on their professional lives. It is also possible that graduate trainees with mental-health difficulties are less likely to ultimately become faculty members, although longitudinal research is needed to empirically test this possibility.

\section{Strengths and limitations}


As with any empirical study, ours has several limitations to consider. Although we attempted to gather the largest possible representative sample of people affiliated with accredited doctoral programs and internships, some eligible individuals may not have had publicly accessible contact information and were thus not notified of the study directly. To address this, we asked recipients of the study advertisement to forward it to others within their program; this expanded the reach of the study but also hampered us from determining an exact response rate. However, our apparent response rate was similar to or greater other studies with overlapping aims (Tay et al., 2018). Further, relative to graduate students and faculty in APA-accredited programs, our sample included comparatively more cisgender women and non-Hispanic/Latinx White individuals than expected (Page et al., 2017), which may have skewed reported prevalence rates relative to true population estimates. In addition, our study targeted only accredited programs in school, clinical, and counseling psychology, so these findings may not apply to psychologists in other areas of psychology that do not engage in clinical care.

Further, our online survey design relied on participants' self-report of mental-health difficulties and diagnoses, which may be incomplete or inaccurate. However, given the professional and educational experiences of the participants in this study, we expect these selfreports to be more accurate than those of the general population. Because of time constraints and the limitations of self-report methodology, we could not assess all aspects of mental-health difficulties, such as the chronology of onset/offset of multiple diagnoses, levels of disclosure, and experiences with treatment. For instance, participants with multiple reported difficulties may have experienced onset earlier for some difficulties than others or may have experienced differing levels of professional problems related to these unique experiences. Further, reported professional problems may not have exclusively occurred during or after psychology graduate 
training and may not be directly comparable with other studies that have focused on “impairment” as a narrower construct.

Although we asked participants whether they experienced mental-health difficulties currently, some variability may exist with respect to how participants operationalized their responses to these questions (e.g., whether they consider themselves in recovery, asymptomatic, or in remission, and how that relates to ongoing treatment, such as medications that ameliorate symptoms). Indeed, it is not uncommon for individuals with lived experience of mental-health difficulties to adopt an array of conceptualizations of recovery and related terms (Drake \& Whitley, 2014). Finally, although our overall sample was large, we could not comment meaningfully on some subgroups, such as postdoctoral trainees or people with disorders uncommon in our sample (e.g., personality disorders, psychotic disorders).

Our study also has several strengths. To date, this is the largest and most comprehensive assessment of mental-health difficulties among applied psychology faculty and trainees, both with respect to sample size and types of difficulties assessed. Our study also employed a systematic recruitment approach, in contrast to more commonly used referral or snowball sampling methods (e.g., Hobaica et al., 2021); used advertisements designed to avoid biasing responses in favor of those with histories of mental-health difficulties; and made efforts to help encourage honest and open reporting of these phenomena (e.g., ensuring participant anonymity).

\section{Future directions}

These data, although critical to fostering discussion of mental-health difficulties within psychological science, are only a first step toward understanding these lived experiences among trainees and faculty within applied disciplines. Our work should spark greater effort to fully understand the experiences of mental-health difficulties, professional problems, disclosure, 
stigma, and professional success in psychological science and practice. In expanding upon this work, we suggest five key areas to guide future investigation:

1. How do mental-health difficulties in clinical, counseling, and school psychology compare with those in other areas of applied psychology that do not involve clinical practice? Or to other mental-health professions, such as psychiatry and social work?

2. How should mental-health difficulties be addressed in clinical training and supervision and to what extent do these experiences influence clinical practice?

3. Why do some people with mental-health difficulties stay in academic psychology, whereas others leave? How can trainees (if they so choose) and faculty with mentalhealth difficulties be supported in pursuing academic careers?

4. How do personal experiences with mental-health difficulties intersect with other identities that have been historically marginalized and excluded from academic spaces, such as individuals from minoritized racial/ethnic, sexual-orientation, and gender-identity groups?

5. What strategies can be implemented at micro and macro levels to increase equity and inclusion for people with mental-health difficulties in psychological science, particularly individuals with mental disorders that can cause significant professional problems?

\section{Conclusions}

These data provide the first large-scale empirical evidence of what many in the field have only discussed behind closed doors: Psychologists have at least their fair share of diagnosed and undiagnosed mental-health difficulties. Although these experiences often have significant emotional, interpersonal, and professional costs, our results also underscore that many people 
with mental-health difficulties are successful psychology trainees and faculty. The common nature of these experiences also underscores the need to finally root out outmoded stigmatizing and silencing views toward mental disorders within psychological science. As scientists, psychologists seek to gather as much data as possible about phenomena of interest, yet we have systematically excluded personal experiences of mental-health difficulties from consideration. These biases have led to a disconnect between the experiences within our own ranks and what we as a field espouse with respect to valuing diversity, equity, and inclusion. We can, and should, do better, not only to improve our professional climate and training environments but also to strengthen our ability to achieve the core mission of applied psychological science, which is to understand and alleviate human suffering. 


\section{Transparency}

Action Editor: Laura A. King

Editor: Laura A. King

Declaration of Conflicting Interests: The author(s) declared that there were no conflicts of interest with respect to the authorship or the publication of this article.

\section{ORCID iDs:}

Sarah E. Victor https://orcid.org/0000-0002-7944-7299

Jonathan Rottenberg https://orcid.org/0000-0001-6128-4359

\section{Supplemental Material:}

Additional supporting information can be found at

http://journals.sagepub.com/doi/suppl/10.1177/17456916211071079 


\section{Acknowledgments}

We are grateful to members of the Tracking Risk over Time Lab (TRTL) at Texas Tech University, namely Abigail Luce, Savannah Goza, Lauren Richardson, Megan Chilton, Terry Trieu, Kirsten Christensen, Michael McClay, and Nicole Seymour, for their assistance in gathering contact information for study participants. We also acknowledge the valuable contributions of our study participants, without whom this project would have been impossible.

Note

1. Beyond domains of psychology involving provision of clinical services, many, if not all, involve translation of science into applied practice. Given this article's focus on data derived from clinical, counseling, and school-psychology programs, the term "clinical" here may be erroneously interpreted to refer only to a subset of these data, and thus we have elected to use the term "applied" only for the sake of brevity. Consideration of the implications of these results to other areas of applied psychology can be found in the Discussion section. 


\section{References}

Andrews, E. E., \& Lund, E. M. (2015). Disability in psychology training: Where are we? Training and Education in Professional Psychology, 9(3), 210-216. http://doi.org/10.1037/tep0000085

Angehrn, A., Vig, K. D., Mason, J. E., Stelnicki, A. M., Shields, R. E., Asmundson, G., \& Carleton, R. N. (2021). Sex differences in mental disorder symptoms among Canadian police officers: The mediating role of social support, stress, and sleep quality. Cognitive Behaviour Therapy. Advance online publication. https://doi.org/gjmr

Appleby, D. C., \& Appleby, K. M. (2006). Kisses of death in the graduate school application process. Teaching of Psychology, 33(1), 19-24. https://doi.org/c2wd2b

Asendorpf, J. B., Conner, M., De Fruyt, F., De Houwer, J., Denissen, J. J. A., Fielder, K., Fielder, S., Funder, D. C., Kliegl, R., Nosek, B. A., Perugini, M., Roberts, B. W., Schmitt, M., van Aken, M. A. G., Weber, H., \& Wicherts, J. M. (2013). Recommendations for increasing replicability in psychology. European Journal of Personality, 27(2), 108-119. https://doi.org/f4wkq2

Bearse, J. L., McMinn, M. R., Seegobin, W., \& Free, K. (2013). Barriers to psychologists seeking mental health care. Professional Psychology: Research and Practice, 44(3), 150157. https://doi.org/10/f425mg

Benuto, L. T., Casas, J., \& O’Donohue, W. T. (2018). Training culturally competent psychologists: A systematic review of the training outcome literature. Training and Education in Professional Psychology, 12(3), 125-134. https://doi.org/gd2ww3

Boysen, G. A., Morton, J., \& Nieves, T. (2019). Kisses of death in the psychology faculty hiring process. Teaching of Psychology, 46(3), 260-266. https://doi.org/10/gf74m6 
Breslau, J., Lane, M., Sampson, N., \& Kessler, R. C. (2008). Mental disorders and subsequent educational attainment in a US national sample. Journal of Psychiatric Research, 42(9), 708-716. https://doi.org/drr2g5

Campbell, A. A., Wisco, B. E., Marx, B. P., \& Pietrzak, R. H. (2018). Association between perceptions of military service and mental health problems in a nationally representative sample of United States military veterans. Psychological Trauma: Theory, Research, Practice, and Policy, 10(4), 482-489. https://doi.org/gdv6dn

Caspi, A., Houts, R. M., Ambler, A., Danese, A., Elliott, M. L., Hariri, A., Harrington, H., Hogan, S., Poulton, R., Ramrakha, S., Rasmussen, L. J. H., Reuben, A., RichmondRakerd, L., Sugden, K., Wertz, J., Williams, B. S., \& Moffitt, T. E. (2020). Longitudinal assessment of mental health disorders and comorbidities across 4 decades among participants in the Dunedin Birth Cohort Study. JAMA Network Open, 3(4), Article e203221. https://doi.org/10/ggsrcz

Charlton, J. I. (1998). Nothing about us without us. University of California Press.

Chiu, M., Amartey, A., Wang, X., Vigod, S., \& Kurdyak, P. (2020). Trends in objectively measured and perceived mental health and use of mental health services: A populationbased study in Ontario, 2002-2014. Canadian Medical Association Journal, 192(13), E329-E337. https://doi.org/gjmv

Chou, T., Asnaani, A., \& Hofmann, S. G. (2012). Perception of racial discrimination and psychopathology across three U.S. ethnic minority groups. Cultural Diversity and Ethnic Minority Psychology, 18(1), 74-81. https://doi.org/10.1037/a0025432 
Cook, B. L., Trinh, N. H., Li, Z., Hou, S. S. Y., \& Progovac, A. M. (2017). Trends in racialethnic disparities in access to mental health care, 2004-2012. Psychiatric Services, 68(1), 9-16. https://doi.org/10.1176/appi.ps.201500453

Dearing, R. L., Maddux, J. E., \& Tangney, J. P. (2005). Predictors of psychological help seeking in clinical and counseling psychology graduate students. Professional Psychology: Research and Practice, 36(3), 323-329. https://doi.org/10/bpwtzw

Devendorf, A. R. (2022). Is "me-search" a kiss of death in mental health research? Psychological Services, 19(1), 49-54. https://doi.org/10.1037/ser0000507w

Drake, R. E., \& Whitley, R. (2014). Recovery and severe mental illness: Description and analysis. The Canadian Journal of Psychiatry, 59(5), 236-242. https://doi.org/10.1177/070674371405900502

Eleftheriades, R., Fiala, C., \& Pasic, M. D. (2020). The challenges and mental health issues of academic trainees. F1000 Research, 9, Article 104. https://doi.org/gg43k2

Elliott, M., \& Ragsdale, J. M. (2020). Mental health professionals with mental illnesses: A qualitative interview study. American Journal of Orthopsychiatry, 90(6), 677-686. https://doi.org/10.1037/ort0000499

Evans, T. M., Bira, L., Gastelum, J. B., Weiss, L. T., \& Vanderford, N. L. (2018). Evidence for a mental health crisis in graduate education. Nature Biotechnology, 36(3), 282-284. https://doi.org/gdjecv

Forsell, Y. (2007). A three-year follow-up of major depression, dysthymia, minor depression and subsyndromal depression: Results from a population-based study. Depression and Anxiety, 24(1), 62-65. https://doi.org/10.1002/da.20231 
Gilroy, P. J., Carroll, L., \& Murra, J. (2002). A preliminary survey of counseling psychologists' personal experiences with depression and treatment. Professional Psychology: Research and Practice, 33(4), 402-407. https://doi.org/10/fs9n2w

Gonzalez, J. M., Alegría, M., Prihoda, T. J., Copeland, L. A., \& Zeber, J. E. (2013). How the relationship of attitudes toward mental health treatment and service use differs by age, gender, ethnicity/race and education. Social Psychiatry and Psychiatric Epidemiology, 46(1), 45-57. https://doi.org/fbj8v7

Gray-Little, B. (2009). The assessment of psychopathology in racial and ethnic minorities. In J. N. Butcher (Ed.), Oxford handbook of personality assessment (pp. 396-414). Oxford University Press.

Grice, T., Alcock, K., \& Scior, K. (2018). Mental health disclosure amongst clinical psychologists in training: Perfectionism and pragmatism. Clinical Psychology \& Psychotherapy, 25(5), 721-729. https://doi.org/10/gfxv4q

Gruber, J., Mendle, J., Lindquist, K. A., Schmader, T., Clark, L. A., Bliss-Moreau, E., Akinola, M., Atlas, L., Barch, D. M., Barrett, L. F., Borelli, J. L., Brannon, T. N., Bunge, S. A., Campos, B., Cantlon, J., Carter, R., Carter-Sowell, A. R., Chen, S., Craske, M. G., .. . Williams, L. A. (2020). The future of women in psychological science. Perspectives on Psychological Science, 16(3), 483-516. https://doi.org/10/gg962n

Hasin, D. S., Sarvet, A. L., Meyers, J. L., Saha, T. D., Ruan, W. J., Stohl, M., \& Grant, B. F. (2018). Epidemiology of adult DSM-5 major depressive disorder and its specifiers in the United States. JAMA Psychiatry, 75(4), 336-346. https://doi.org/ggs69d

Henrich, J., Heine, S. J., \& Norenzayan, A. (2010). Most people are not WEIRD. Nature, 466(7302), 29-29. https://doi.org/cjv3sq 
Hobaica, S., Szkody, E., Owens, S. A., Boland, J. K., Washburn, J. J., \& Bell, D. J. (2021). Mental health concerns and barriers to care among future clinical psychologists. Journal of Clinical Psychology, 77(11), 2473-2490. https://doi.org/10.1002/jclp.23198

Hyun, J. K., Quinn, B. C., Madon, T., \& Lustig, S. (2006). Graduate student mental health: Needs assessment and utilization of counseling services. Journal of College Student Development, 47(3), 247-266. https://doi.org/10/bh2h7f

Jones, N., Atterbury, K., Byrne, L., Carras, M., Brown, M., \& Phalen, P. (2021). Lived experience, research leadership, and the transformation of mental health services: Building a researcher pipeline. Psychiatric Services, 72(5), 591-593. https://doi.org/10/gjn3h8

Joseph, K. M., Barnes, T., Harris, J. I., \& Boyd, J. (2022). Disclosure of lived experience of mental illness in training: Reasons for disclosure. Psychological Services, 19(1), 69-72. https://doi.org/10.1037/ser0000536

Kazdin, A. E., \& Blase, S. L. (2011). Rebooting psychotherapy research and practice to reduce the burden of mental illness. Perspectives on Psychological Science, 6(1), 21-37. https://doi.org/cnm63t

Kessler, R. C. (2004). Gender differences in mental disorders in the U.S. National Comorbidity Survey. In D. E. Marcotte \& V. Wilcox (Eds.), Research in human capital and development: The economics of gender and mental illness (Vol. 15, pp. 7-25). Emerald.

Kessler, R. C., Berglund, P., Demler, O., Jin, R., Merikangas, K. R., \& Walters, E. E. (2005). Lifetime prevalence and age-of-onset distributions of DSM-IV disorders in the National Comorbidity Survey Replication. Archives of General Psychiatry, 62, 593-602. https://doi.org/10/b3b2pv 
Kotov, R., Krueger, R. F., Watson, D., Achenbach, T. M., Althoff, R. R., Bagby, R. M., Brown, T. A., Carpenter, W. T., Caspi, A., Clark, L. A., Eaton, N. R., Forbes, M. K., Forbush, K. T., Goldberg, D., Hasin, D., Hyman, S. E., Ivanova, M. Y., Lynam, D. R., Markon, K., . . . Zimmerman, M. (2017). The Hierarchical Taxonomy of Psychopathology (HiTOP): A dimensional alternative to traditional nosologies. Journal of Abnormal Psychology, 126(4), 454-477. https://doi.org/10/gckfz4

Levecque, K., Anseel, F., De Beuckelaer, A., Van der Heyden, J., \& Gisle, L. (2017). Work organization and mental health problems in PhD students. Research Policy, 46(4), 868879. https://doi.org/10/b4wm

Lipson, S. K., Zhou, S., Wagner, B., Beck, K., \& Eisenberg, D. (2016). Major differences: Variations in undergraduate and graduate student mental health and treatment utilization across academic disciplines. Journal of College Student Psychotherapy, 30(1), 23-41. https://doi.org/10/ gfgx9z

Maranzan, K. A. (2016). Addressing mental illness stigma in the psychology classroom. Psychology Learning \& Teaching, 15(3), 235-249. https://doi.org/ggkjxc

Neblett, E. W. (2019). Diversity (psychological) science training: Challenges, tensions, and a call to action. Journal of Social Issues, 75(4), 1216-1239. https://doi.org/ghvdxp

Page, C., Buche, J., Beck, A. J., Stamm, K., Lin, L., \& Christidis, P. (2017). Understanding the diversity of students and faculty in health service psychology doctoral programs. University of Michigan Behavioral Health Workforce Research Center. https://www.behavioralhealthworkforce.org/Report.pdf

Peluso, D. L., Carleton, R. N., \& Asmundson, G. J. G. (2011). Depression symptoms in Canadian psychology graduate students: Do research productivity, funding, and the 
academic advisory relationship play a role? Canadian Journal of Behavioural Science, 43(2), 119-127. https://doi.org/10/dmgm7h

Pope, K. S., \& Tabachnick, B. (1994). Therapists as patients: A national survey of psychologists' experiences, problems, and beliefs. Professional Psychology: Research and Practice, 25(3), 247-258. https://doi.org/10/dqq2b5

Pope, K. S., Tabachnick, B. G., \& Keith-Spiegel, P. (1987). Ethics of practice: The beliefs and behaviors of psychologists as therapists. American Psychologist, 42(11), 993- 1006. https://doi.org/10/ccmh3w

Price, M., Salzer, M. S., O’Shea, A., \& Kerschbaum, S. L. (2017). Disclosure of mental disability by college and university faculty: The negotiation of accommodations, supports, and barriers. Disability Studies Quarterly, 37(2), Article 5487. https://doi.org/10/gjn3jz

Royalty, G. M., \& Reising, G. N. (1986). The research training of counseling psychologists: What the professionals say. The Counseling Psychologist, 14(1), 49-60. https://doi.org/d9wzfp

Servais, L. M., \& Saunders, S. M. (2007). Clinical psychologists' perceptions of persons with mental illness. Professional Psychology: Research and Practice, 38(2), 214-219. https://doi.org/10/ckvrsp

Smith, P. L., \& Moss, S. B. (2009). Psychologist impairment: What is it, how can it be prevented, and what can be done to address it? Clinical Psychology: Science and Practice, 16(1), 1-15. https://doi.org/10/bt878d

Statistics Canada. (2014, February 11). Mental health indicators. https://www150.statcan.gc.ca/t1/tbl1/en/tv.action? pid=1310046501 
Stewart, C. E., Lee, S. Y., Hogstrom, A., \& Williams, M. (2017). Diversify and conquer: A call to promote minority representation in clinical psychology. The Behavior Therapist, 40(3), 74-79.

Tay, S., Alcock, K., \& Scior, K. (2018). Mental health problems among clinical psychologists: Stigma and its impact on disclosure and help-seeking. Journal of Clinical Psychology, 74(9), 1545-1555. https://doi.org/10/gfqwxx

Thoreson, R. W., \& Miller, M. (1989). The distressed psychologist: Prevalence and treatment considerations. Professional Psychology: Research and Practice, 20(3), 153-158. https://doi.org/bcw2rx

Twenge, J. M., Cooper, A. B., Joiner, T. E., Duffy, M. E., \& Binau, S. G. (2019). Age, period, and cohort trends in mood disorder indicators and suicide-related outcomes in a nationally representative dataset, 2005-2017. Journal of Abnormal Psychology, 128(3), 185-199. https://doi.org/10/gfxvz9

Victor, S. E., Lewis, S. P., \& Muehlenkamp, J. J. (2022). Psychologists with lived experience of non-suicidal self-injury: Priorities, obstacles, and recommendations for inclusion. Psychological Services, 19(1), 21-28. https://doi.org/10.1037/ser0000510

Vierthaler, J. M., \& Elliott, E. C. (2020). A shared lived experience of a psychologist battling a mental health crisis. Psychological Services. Advance online publication. https://doi.org/gjnb

Wahl, O., \& Aroesty-Cohen, E. (2010). Attitudes of mental health professionals about mental illness: A review of the recent literature. Journal of Community Psychology, 38(1), 4962. https://doi.org/c9j4vj 
Wang, P. S., Berglund, P., Olfson, M., Pincus, H. A., Wells, K. B., \& Kessler, R. C. (2005). Failure and delay in initial treatment contact after first onset of mental disorders in the National Comorbidity Survey Replication. Archives of General Psychiatry, 62(6), 603613. https://doi.org/10.1001/archpsyc.62.6.603

Washburn, A. N., Hanson, B. E., Motyl, M., Skitka, L. J., Yantis, C., Wong, K. M., Sun, J., Prims, J. P., Mueller, A. B., Melton, Z. J., \& Carsel, T. S. (2018). Why do some psychology researchers resist adopting proposed reforms to research practices? A description of researchers' rationales. Advances in Methods and Practices in Psychological Science, 1(2), 166-173. https://doi.org/10.1177/2515245918757427 
Table 1. Group Comparisons on Characteristics of Mental-Health Difficulties and Diagnoses

\begin{tabular}{|c|c|c|c|}
\hline Characteristic & $\begin{array}{l}\text { Undiagnosed mental- } \\
\text { health difficulties }\end{array}$ & $\begin{array}{c}\text { Diagnosed } \\
\text { mental disorders }\end{array}$ & $\chi^{2}(d f, N)$ \\
\hline Onset & & & $69.80(2, N=1,378)^{*}$ \\
\hline Before graduate school & $427(73.24) \mathrm{a}$ & $718(90.31) b$ & \\
\hline During graduate school & $125(21.44) \mathrm{a}$ & $61(7.67) b$ & \\
\hline After graduate school & $31(5.32) \mathrm{a}$ & $16(2.01) b$ & \\
\hline Offset & & & $93.74(3, N=1,377)^{*}$ \\
\hline None (current) & $173(29.73) \mathrm{a}$ & $435(54.72) b$ & \\
\hline Within the past year (not current) & $141(24.23) \mathrm{a}$ & $155(19.50) \mathrm{b}$ & \\
\hline Within the past 5 years (not past year) & $124(21.31) \mathrm{a}$ & $110(13.84) b$ & \\
\hline Before 5 years ago & $144(24.74) \mathrm{a}$ & $95(11.95) \mathrm{b}$ & \\
\hline Professional problems & & & $63.67(2, N=1,355)^{*}$ \\
\hline None & $351(60.0) \mathrm{a}$ & $319(40.08) b$ & \\
\hline Mild & $208(35.56) \mathrm{a}$ & $350(43.97) b$ & \\
\hline Moderate & $23(3.93) \mathrm{a}$ & $104(13.07) \mathrm{b}$ & \\
\hline Severe & $3(0.51)$ & $23(2.89)$ & \\
\hline Domains of professional problems & & & \\
\hline Clinical practice & $56(23.93)$ & $147(30.82)$ & $3.65(1, N=711)$ \\
\hline Clinical supervision & $21(8.97)$ & $58(12.16)$ & $1.61(1, N=711)$ \\
\hline Research & $141(60.26)$ & $294(61.64)$ & $0.13(1, N=711)$ \\
\hline Coursework (as a student) & $129(55.13)$ & $262(54.93)$ & $0.003(1, N=711)$ \\
\hline Teaching (as TA or faculty) & $42(17.95)$ & $101(21.17)$ & $1.02(1, N=711)$ \\
\hline Other & $34(14.53)$ & $67(14.05)$ & $0.03(1, N=711)$ \\
\hline
\end{tabular}

Note: Values are $n$ s with percentages in parentheses. Domains of professional problems were assessed only for respondents reporting at least mild problems $(n=711)$, and participants could mark multiple problem domains. Values sharing a common subscript are not significantly different from each other; cells without subscript letters were not included in omnibus $\chi 2$ tests because of small cell sizes. $\mathrm{TA}=$ teaching assistant.

$* p<.05$. 
Table 2. Group Comparisons on Demographic Characteristics

\begin{tabular}{|c|c|c|c|c|}
\hline Characteristic & $\begin{array}{l}\text { No mental- } \\
\text { health } \\
\text { difficulties }\end{array}$ & $\begin{array}{l}\text { Undiagnosed } \\
\text { mental-health } \\
\text { difficulties }\end{array}$ & $\begin{array}{l}\text { Diagnosed } \\
\text { mental } \\
\text { disorders }\end{array}$ & $\chi^{2}(d f, N)$ \\
\hline Gender & & & & $28.14(2, N=1,649)^{*}$ \\
\hline Cisgender woman & $92(27.38) \mathrm{a}$ & $115(34.23) \mathrm{a}$ & $129(38.39) \mathrm{a}$ & \\
\hline Cisgender man & $202(15.38) b$ & $468(35.64) a$ & $643(48.97) b$ & \\
\hline Nonbinary/gender nonconforming & $0(0.0)$ & $3(12.50)$ & $21(87.50)$ & \\
\hline Other & $0(0.0)$ & $1(20.0)$ & $4(80.0)$ & \\
\hline Transgender man & $0(0.0)$ & $0(0.0)$ & $3(1.0)$ & \\
\hline $\begin{array}{l}\text { Transgender woman } \\
\text { Race/ethnicity }\end{array}$ & $0(0.0)$ & $0(0.0)$ & $1(1.0)$ & $26.92(8, N=1,658)^{*}$ \\
\hline Non-Hispanic White & $223(17.38) \mathrm{a}$ & $429(33.44) \mathrm{a}$ & $631(49.18) \mathrm{a}$ & \\
\hline Hispanic/Latinx & $20(18.52) a, b$ & $37(34.26) \mathrm{a}$ & $51(47.22) a, b$ & \\
\hline Multiracial/Biracial/other & $7(6.36) b$ & $46(41.82) a$ & $57(51.82) \mathrm{a}, \mathrm{b}$ & \\
\hline Asian/Asian American/Canadian & $21(21.88) \mathrm{a}$ & 43 (44.79)a & $32(33.33) b$ & \\
\hline Black/African American/Canadian & $19(31.15) \mathrm{a}$ & $17(27.87) \mathrm{a}$ & $25(40.98) a, b$ & \\
\hline Middle Eastern/North African & $1(5.26)$ & $13(68.42)$ & $5(26.32)$ & \\
\hline Native American/First Nations/Alaskan Native & $1(50.0)$ & $0(0.0)$ & $1(50.0)$ & \\
\hline $\begin{array}{l}\text { Native Hawaiian/Pacific Islander } \\
\text { Sexual orientation }\end{array}$ & $0(0.0)$ & $1(1.0)$ & $0(0.0)$ & $73.10(4, N=1,578)^{*}$ \\
\hline Heterosexual/straight & $270(20.56) \mathrm{a}$ & $491(37.40) \mathrm{a}$ & $552(42.04) \mathrm{a}$ & \\
\hline Bisexual & $9(5.20) \mathrm{b}$ & $39(22.54) b$ & $125(72.25) \mathrm{b}$ & \\
\hline Homosexual/gay/lesbian & $7(7.61) b$ & $26(28.26) a, b$ & $59(64.13) b$ & \\
\hline Other & $0(0.0)$ & $16(39.02)$ & $25(60.98)$ & \\
\hline Pansexual & $2(4.76)$ & $11(26.19)$ & $29(69.05)$ & \\
\hline Asexual & $0(0.0)$ & $1(12.50)$ & $7(87.50)$ & \\
\hline
\end{tabular}

Note: Values are $n \mathrm{~s}$ with percentages in parentheses. Values sharing a common subscript are not significantly different from each other; cells without subscript letters were not included in omnibus $\chi 2$ tests because of small cell sizes.

$* p<.05$. 
Table 3. Group Comparisons on Professional and Program Characteristics

\begin{tabular}{|c|c|c|c|c|}
\hline Characteristic & $\begin{array}{c}\text { No mental-health } \\
\text { difficulties }\end{array}$ & $\begin{array}{l}\text { Undiagnosed mental- } \\
\text { health difficulties }\end{array}$ & $\begin{array}{c}\text { Diagnosed mental } \\
\text { disorders }\end{array}$ & $\chi^{2}(d f, N)$ \\
\hline Primary status & & & & $91.58(8, N=1,685)^{*}$ \\
\hline Graduate student & $115(11.14) \mathrm{a}$ & $377(36.53) \mathrm{a}$ & $540(52.33) \mathrm{a}$ & \\
\hline Faculty & $132(29.20) \mathrm{c}$ & $137(30.31) a$ & $183(40.49) \mathrm{b}$ & \\
\hline Clinician & $33(26.40) b, c$ & $40(32.0) \mathrm{a}$ & $52(41.60) a, b$ & \\
\hline Postdoc & $5(10.20) a, b$ & $23(46.94) \mathrm{a}$ & $21(42.86) a, b$ & \\
\hline Other & $10(37.04) \mathrm{c}$ & $10(37.04) \mathrm{a}$ & $7(25.93) a, b$ & \\
\hline Program accreditation & & & & $13.59(2, N=1,645)^{*}$ \\
\hline APA & $246(17.05) \mathrm{a}$ & $485(33.61) \mathrm{a}$ & $712(49.34) \mathrm{a}$ & \\
\hline CPA & $41(20.30) a$ & $89(44.06) \mathrm{b}$ & $72(35.64) b$ & \\
\hline Program training model & & & & $15.72(6, N=1,605)^{*}$ \\
\hline Scientist-practitioner & $189(18.69) \mathrm{a}$ & $373(36.89) \mathrm{a}$ & $449(44.41) \mathrm{a}$ & \\
\hline Clinical science & $37(12.94) a$ & $93(32.52) \mathrm{a}$ & $156(54.55) \mathrm{b}$ & \\
\hline Practitioner-scholar & $47(18.36) \mathrm{a}$ & $73(28.52) \mathrm{a}$ & $136(53.13) \mathrm{a}, \mathrm{b}$ & \\
\hline Other & $9(17.31) \mathrm{a}$ & $17(32.69) \mathrm{a}$ & $26(50.0) a, b$ & \\
\hline Program type & & & & $16.64(10, N=1,679)$ \\
\hline Doctoral $(\mathrm{PhD})$ & $205(16.90) \mathrm{a}$ & $441(36.36) \mathrm{a}$ & $567(46.74) \mathrm{a}$ & \\
\hline Doctoral (PsyD) & $38(16.52) \mathrm{a}$ & $68(29.57) \mathrm{a}$ & $124(53.91) a$ & \\
\hline Internship & $28(21.71) \mathrm{a}$ & $36(27.91) \mathrm{a}$ & $65(50.39) \mathrm{a}$ & \\
\hline Postdoctoral & $5(13.16) \mathrm{a}$ & $17(44.74) \mathrm{a}$ & $16(42.11) \mathrm{a}$ & \\
\hline Other & $12(30.77) \mathrm{a}$ & $15(38.46) \mathrm{a}$ & $12(30.77) \mathrm{a}$ & \\
\hline Master's & $6(20.0) a$ & $10(33.33) \mathrm{a}$ & $14(46.67) \mathrm{a}$ & \\
\hline Doctoral (EdD) & $0(0.0)$ & $0(0.0)$ & $2(1.0)$ & \\
\hline Bachelor's & $0(0.0)$ & $0(0.0)$ & $1(1.0)$ & \\
\hline Area of study & & & & $14.67(8, N=1,685)$ \\
\hline Clinical & $203(16.71) \mathrm{a}$ & $431(35.47) \mathrm{a}$ & $581(47.82) \mathrm{a}$ & \\
\hline Counseling & $24(13.79) \mathrm{a}$ & $56(32.18) \mathrm{a}$ & $94(54.02) \mathrm{a}$ & \\
\hline School & $32(24.06) \mathrm{a}$ & $49(36.84) \mathrm{a}$ & $52(39.10) \mathrm{a}$ & \\
\hline Combined (more than one of the above) & $18(23.38) \mathrm{a}$ & $19(24.68) \mathrm{a}$ & $40(51.95) \mathrm{a}$ & \\
\hline Other (none of the above) & $18(20.93) \mathrm{a}$ & $32(37.21) \mathrm{a}$ & $36(41.86) \mathrm{a}$ & \\
\hline
\end{tabular}

Note: Values are $n$ s with percentages in parentheses. Values sharing a common subscript are not significantly different from each other; cells without subscript letters were not

included in omnibus $\chi 2$ tests because of small cell sizes. APA $=$ American Psychological Association; CPA $=$ Canadian Psychological Association. $* p<.05$. 
Table 4. Group Comparisons Between Students and Faculty on Characteristics of Mental-Health Difficulties and Diagnoses

\begin{tabular}{|c|c|c|c|}
\hline Characteristic & Student & Faculty & $\chi^{2}(d f, N)$ \\
\hline Onset & & & $8.91(1, N=1,195)^{*}$ \\
\hline $\begin{array}{l}\text { Before graduate school } \\
\text { During graduate school } \\
\text { After graduate school } \\
\text { Offset }\end{array}$ & $\begin{array}{l}807(88.48) \mathrm{a} \\
105(11.51) \mathrm{a} \\
\quad 0(0.0)\end{array}$ & $\begin{array}{l}231(71.73) b \\
52(16.14) b \\
39(12.11)\end{array}$ & $203.35(3, N=1,233)^{*}$ \\
\hline $\begin{array}{l}\text { None (current) } \\
\text { Within the past year (not current) } \\
\text { Within the past } 5 \text { years (not past year) } \\
\text { Before } 5 \text { years ago } \\
\text { Professional problems }\end{array}$ & $\begin{array}{l}480(52.74) \mathrm{b} \\
203(22.30) \mathrm{a} \\
158(17.36) \mathrm{a} \\
69(7.58) \mathrm{b}\end{array}$ & $\begin{array}{l}82(25.38) \mathrm{a} \\
61(18.88) \mathrm{a} \\
48(14.86) \mathrm{a} \\
132(40.86) \mathrm{a}\end{array}$ & $9.97(3, N=1,238)^{*}$ \\
\hline $\begin{array}{l}\text { None } \\
\text { Mild } \\
\text { Moderate } \\
\text { Severe }\end{array}$ & $\begin{array}{c}409(44.74) \mathrm{b} \\
395(43.21) \mathrm{b} \\
90(9.84) \mathrm{a} \\
20(2.18) \mathrm{a}\end{array}$ & $\begin{array}{l}175(54.01) \mathrm{a} \\
109(33.64) \mathrm{a} \\
34(10.49) \mathrm{a} \\
6(1.85) \mathrm{a}\end{array}$ & \\
\hline $\begin{array}{l}\text { Domains of professional problems } \\
\text { Clinical practice }\end{array}$ & $153(30.29)$ & $34(21.47)$ & $3.15(1, N=654)$ \\
\hline Clinical supervision & $54(10.69)$ & $21(14.09)$ & $1.31(1, N=654)$ \\
\hline Research & $317(62.77)$ & $98(65.77)$ & $0.45(1, N=654)$ \\
\hline Coursework (as a student) & $332(65.74)$ & $37(24.83)$ & $78.32(1, N=654)^{*}$ \\
\hline Teaching (as TA or faculty) & $81(25.0)$ & $56(37.58)$ & $32.25(1, N=654)^{*}$ \\
\hline Other & $51(15.74)$ & $31(20.80)$ & $12.03(1, N=654)^{*}$ \\
\hline
\end{tabular}

Note: Values are $n \mathrm{~s}$ with percentages in parentheses. Domains of professional problems were assessed only for respondents reporting at least mild problems $(n=654)$, and participants could mark multiple problem domains. Values sharing a common subscript are not significantly different from each other; cells without subscript letters were not included in omnibus $\chi^{2}$ tests because of small cell sizes. $\mathrm{TA}=$ teaching assistant.

$* p<.05$. 


\section{Table S1}

\section{Sample Characteristics}

\begin{tabular}{|c|c|}
\hline Professional and Program Characteristics & $N(\%)$ \\
\hline \multicolumn{2}{|l|}{ Primary Status $(n=1958)$} \\
\hline Graduate student & $1172(59.86)$ \\
\hline Faculty & $541(27.63)$ \\
\hline Clinician & $152(7.76)$ \\
\hline Postdoc & $60(3.06)$ \\
\hline Other & $33(1.69)$ \\
\hline \multicolumn{2}{|l|}{ Current Program Accreditation $(n=1856)$} \\
\hline American Psychological Association & $1615(87.02)$ \\
\hline Psychological Clinical Science Accreditation System & $247(13.31)$ \\
\hline Association of Psychology Postdoctoral and Internship Centers & $233(12.55)$ \\
\hline Canadian Psychological Association & $226(12.18)$ \\
\hline Other & $97(5.23)$ \\
\hline Don't know & $31(1.67)$ \\
\hline \multicolumn{2}{|l|}{ Current Program Training Model $(n=1775)$} \\
\hline Scientist-practitioner & $1114(62.76)$ \\
\hline Clinical science & $313(17.63)$ \\
\hline Practitioner-scholar & $292(16.45)$ \\
\hline Other & $56(3.15)$ \\
\hline \multicolumn{2}{|l|}{ Current Program Type $(n=1868)$} \\
\hline Doctoral (PhD) & $1342(71.84)$ \\
\hline Doctoral (PsyD) & 265 (14.19) \\
\hline Internship & $139(7.44)$ \\
\hline Postdoctoral & $43(2.30)$ \\
\hline Other & $42(2.25)$ \\
\hline Master's & $34(1.82)$ \\
\hline Doctoral (EdD) & $2(0.11)$ \\
\hline Bachelor's & $1(0.05)$ \\
\hline \multicolumn{2}{|l|}{ Degree Sought (Students Only, $n=1129$ ) } \\
\hline $\mathrm{PhD}$ & $930(82.37)$ \\
\hline PsyD & $162(14.35)$ \\
\hline Masters & $26(2.30)$ \\
\hline Other & $11(0.97)$ \\
\hline \multicolumn{2}{|l|}{ Year in Training (Students Only, $n=1128$ ) } \\
\hline First & $254(22.52)$ \\
\hline Third & $202(17.91)$ \\
\hline Fourth & $195(17.29)$ \\
\hline Second & $188(16.67)$ \\
\hline Fifth & $175(15.51)$ \\
\hline Sixth & $87(7.71)$ \\
\hline Seventh or above & $27(2.39)$ \\
\hline
\end{tabular}


Full Professor

$182(30.43)$

Assistant Professor

$169(28.26)$

Associate Professor

$138(23.08)$

Postdoc

$50(8.36)$

Other

$48(8.03)$

Adjunct

$6(1.00)$

Lecturer

$3(0.50)$

Visiting Assistant Professor

$2(0.33)$

Graduate Institution Training Model (Non-Students Only, $n=724$ )

Scientist-practitioner

499 (68.92)

Practitioner-scholar

$98(13.54)$

Clinical science

$93(12.85)$

Other

34 (4.70)

Highest Education Completed (Non-Students Only, $n=785$ )

Doctorate

$767(97.71)$

Masters

$11(1.40)$

Professional Degree

$5(0.64)$

Bachelors

$2(0.25)$

Professional Area(s) of Study $(n=1871)$

Clinical

$1419(75.84)$

Counseling

$243(12.99)$

School

$210(11.22)$

Health

$164(8.77)$

Neuropsychology

$132(7.06)$

Forensic

$81(4.33)$

Developmental

$78(4.17)$

Other

69 (3.69)

Neuroscience

$59(3.15)$

Personality

$39(2.08)$

Community

$30(1.60)$

Cognitive

$29(1.55)$

Social

27 (1.44)

Cultural

$23(1.23)$

Rehabilitation

$18(0.96)$

Educational

$13(0.69)$

Industrial-Organizational

$5(0.27)$

Human factors

$5(0.27)$

Demographic Characteristics $N(\%)$

\section{Gender}

Cisgender woman

$1523(77.94)$

Cisgender man

394 (20.16)

Non-binary / gender non-conforming

$23(1.18)$

Other

$5(0.26)$

Transgender man

$4(0.20)$

Transgender woman

$1(0.05)$

Race/Ethnicity 
Non-Hispanic white

$1480(75.94)$

Hispanic / Latinx

$133(6.82)$

Multiracial / Biracial / Other

$128(6.57)$

Asian / Asian-American/Canadian

$116(5.95)$

Black /African-American/Canadian

$66(3.39)$

Middle Eastern / North African

$22(1.13)$

Native American / First Nations / Alaskan Native

Native Hawaiian / Pacific Islander

$1(0.05)$

Sexual Orientation

Heterosexual / straight

$1526(78.82)$

Bisexual

$201(10.38)$

Homosexual / gay / lesbian

$109(5.63)$

Pansexual

$46(2.38)$

Other

$46(2.38)$

Asexual

$8(0.41)$ 


\section{Table S2}

Demographic Characteristics and Comparisons of Students and Faculty

\begin{tabular}{|c|c|c|c|}
\hline & $\begin{array}{c}\text { Student } n \\
(\%)\end{array}$ & $\begin{array}{c}\text { Faculty } n \\
(\%)\end{array}$ & $X^{2}(d f)$ \\
\hline Gender & & & $144.11(1)^{*}$ \\
\hline Cisgender woman & $999(85.38)^{\mathrm{a}}$ & $335(62.15)^{b}$ & \\
\hline Cisgender man & $140(11.97)^{\mathrm{a}}$ & $202(37.48)^{b}$ & \\
\hline Non-binary / gender non-conforming & $21(1.79)$ & $2(0.37)$ & \\
\hline Other & $5(0.43)$ & $0(0.0)$ & \\
\hline Transgender man & $4(0.34)$ & $0(0.0)$ & \\
\hline Transgender woman & $1(0.09)$ & $0(0.0)$ & \\
\hline Race/Ethnicity & & & $26.12(4)^{*}$ \\
\hline Non-Hispanic white & $843(71.99)^{b}$ & $442(82.93)^{\mathrm{a}}$ & \\
\hline Hispanic / Latinx & $84(7.17)^{\mathrm{a}}$ & $35(6.57)^{\mathrm{a}}$ & \\
\hline Multiracial / Biracial / Other & $90(7.69)^{\mathrm{b}}$ & $25(4.69)^{\mathrm{a}}$ & \\
\hline Asian / Asian-American/Canadian & $89(7.60)^{b}$ & $15(2.81)^{\mathrm{a}}$ & \\
\hline Black/African-American/Canadian & $43(3.67)^{\mathrm{a}}$ & $13(2.44)^{\mathrm{a}}$ & \\
\hline Middle Eastern / North African & $19(1.62)$ & $3(0.56)$ & \\
\hline Native American/First Nations/Alaskan Native & $2(0.17)$ & $0(0.0)$ & \\
\hline Native Hawaiian / Pacific Islander & $1(0.09)$ & $0(0.0)$ & \\
\hline Sexual Orientation & & & $42.81(3)^{*}$ \\
\hline Heterosexual / straight & $856(73.73)^{b}$ & $464(87.38)^{\mathrm{a}}$ & \\
\hline Bisexual & $162(13.95)^{b}$ & $23(4.33)^{\mathrm{a}}$ & \\
\hline Homosexual / gay / lesbian & $67(5.77)^{\mathrm{a}}$ & $33(6.21)^{\mathrm{a}}$ & \\
\hline Other & $34(2.93)^{b}$ & $7(1.32)^{\mathrm{a}}$ & \\
\hline Pansexual & $34(2.93)$ & $4(0.75)$ & \\
\hline Asexual & $8(0.69)$ & $0(0.0)$ & \\
\hline
\end{tabular}

Note. Values that differ in superscript letter differ significantly from each other; cells without

superscript letters were not included in omnibus $\mathrm{X}^{2}$ tests due to small cell sizes. Statistically significant values at $p<.05$ are indicated by an asterisk. 


\section{Table S3}

Specific Mental Health Difficulties among Participants with Any Mental Health Difficulties

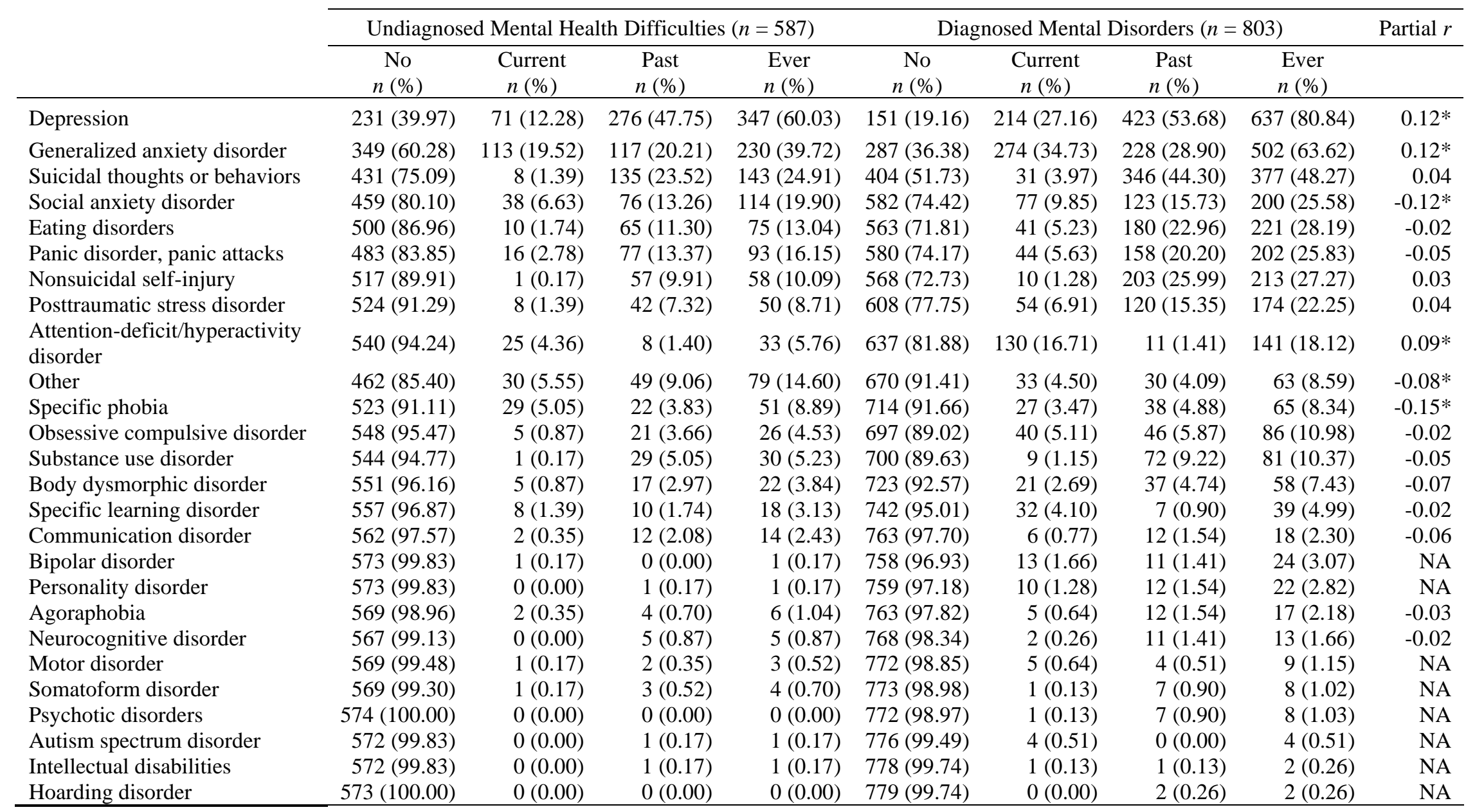

Note. The "ever" column reflects the sum of individuals who endorsed experiencing a specific mental health difficulty either currently

or in the past. These data are drawn only from individuals who reported lifetime undiagnosed or diagnosed mental health difficulties, 
excluding participants in the no mental health difficulties group $(n=295)$. Thus, to estimate the prevalence of a specific mental health difficulty in the full sample, divide the sum of the "ever" columns for participants with undiagnosed and diagnosed mental health difficulties by the total sample size for all three groups together $(N=1695)$. For details regarding the specific phrasing of the above items, see the survey instrument on Open Science Framework (link in text). Partial $r$ values reflect a partial phi coefficient (correlation between two binary variables, group status and "ever" mental health difficulty yes/no) controlling for number of total diagnoses. "NA" reflects statistical tests not conducted due to small cell sizes. Statistically significant values at $p<.01$, adjusted for multiple comparisons, are indicated by an asterisk. 


\section{Table S4}

Group Comparisons between Students and Faculty on Characteristics of Mental Health

Difficulties and Diagnoses - Separated by Group

\begin{tabular}{|c|c|c|c|}
\hline & $\begin{array}{c}\text { Student } \\
n(\%)\end{array}$ & $\begin{array}{c}\text { Faculty } \\
n(\%)\end{array}$ & $X^{2}(d f)$ \\
\hline \multicolumn{4}{|c|}{ Undiagnosed Mental Health Difficulties Group } \\
\hline Onset & & & $1.14(1)$ \\
\hline Prior to graduate school & $295(78.88)^{\mathrm{a}}$ & $83(61.03)^{\mathrm{a}}$ & \\
\hline During graduate school & $79(21.12)^{\mathrm{a}}$ & $29(21.32)^{\mathrm{a}}$ & \\
\hline After graduate school & $0(0.0)$ & $24(17.65)$ & \\
\hline Offset & & & $114.95(13)^{*}$ \\
\hline None (current) & $146(39.35)^{b}$ & $17(12.41)^{\mathrm{a}}$ & \\
\hline Within the past year (not current) & $106(28.49)^{b}$ & $18(13.14)^{\mathrm{a}}$ & \\
\hline Within the past five years (not past year) & $77(20.70)^{\mathrm{a}}$ & $26(18.98)^{\mathrm{a}}$ & \\
\hline Prior to five years ago & $43(11.56)^{b}$ & $76(55.47)^{\mathrm{a}}$ & \\
\hline Professional Problems & & & $4.07(1)$ \\
\hline None & $206(54.93)^{b}$ & $89(64.96)^{\mathrm{a}}$ & \\
\hline Mild & $150(40.0)^{\mathrm{b}}$ & $42(30.66)^{\mathrm{a}}$ & \\
\hline Moderate & $18(4.80)$ & $4(2.92)$ & \\
\hline Severe & $1(0.27)$ & $2(1.46)$ & \\
\hline \multicolumn{4}{|l|}{ Domains of Professional Problems } \\
\hline Clinical Practice & $43(25.44)$ & $9(18.75)$ & $0.92(1)$ \\
\hline Clinical Supervision & $17(10.06)$ & $3(6.25)$ & NA \\
\hline Research & $102(60.36)$ & $30(62.50)$ & $0.07(1)$ \\
\hline Coursework (as a Student) & $106(62.72)$ & $14(29.17)$ & $17.03(1)^{*}$ \\
\hline Teaching (as TA or faculty) & $24(14.20)$ & $16(33.33)$ & $9.10(1)^{*}$ \\
\hline Other & $20(11.83)$ & $10(20.83)$ & $2.54(1)$ \\
\hline \multicolumn{4}{|l|}{ Diagnosed Mental Disorders Group } \\
\hline Onset & & & $15.32(1)^{*}$ \\
\hline Prior to graduate school & $508(95.13)^{b}$ & $145(80.11)^{\mathrm{a}}$ & \\
\hline During graduate school & $26(4.87)^{b}$ & $23(12.71)^{\mathrm{a}}$ & \\
\hline After graduate school & $0(0.0)$ & $13(7.18)$ & \\
\hline Offset & & & $96.97(3)^{*}$ \\
\hline None (current) & $332(62.17)^{\mathrm{b}}$ & $64(35.36)^{\mathrm{a}}$ & \\
\hline Within the past year (not current) & $95(17.79)^{\mathrm{a}}$ & $43(23.76)^{\mathrm{a}}$ & \\
\hline Within the past five years (not past year) & $81(15.17)^{\mathrm{a}}$ & $20(11.05)^{\mathrm{a}}$ & \\
\hline Prior to five years ago & $26(4.87)^{\mathrm{b}}$ & $54(29.83)^{\mathrm{a}}$ & \\
\hline Professional Problems & & & $5.08(2)$ \\
\hline None & $199(37.27)^{\mathrm{a}}$ & $82(45.05)^{\mathrm{a}}$ & \\
\hline Mild & $244(45.69)^{b}$ & $67(36.81)^{\mathrm{a}}$ & \\
\hline Moderate & $72(13.48)^{\mathrm{a}}$ & $29(15.93)^{\mathrm{a}}$ & \\
\hline Severe & $19(3.56)$ & $4(2.20)$ & \\
\hline
\end{tabular}

Domains of Professional Problems 


\begin{tabular}{lrrr}
\hline Clinical Practice & $110(32.84)$ & $25(25.0)$ & $2.21(1)$ \\
Clinical Supervision & $37(11.04)$ & $18(18.0)$ & $3.37(1)$ \\
Research & $214(63.88)$ & $67(67.0)$ & $0.33(1)$ \\
Coursework (as a Student) & $226(67.46)$ & $23(23.0)$ & $62.20(1)^{*}$ \\
Teaching (as TA or faculty) & $57(17.01)$ & $40(40.0)$ & $23.48(1)^{*}$ \\
Other & $31(9.25)$ & $20(20.0)$ & $8.59(1)^{*}$ \\
\hline
\end{tabular}

Note. Domains of professional problems were assessed only for respondents reporting at least mild problems (undiagnosed mental health difficulties $n=217$; diagnosed mental disorders $n=$ 435), and participants could mark multiple problem domains. "NA" reflects statistical tests not conducted due to small cell sizes. Values that differ in superscript letter differ significantly from each other; cells without superscript letters were not included in omnibus $\mathrm{X}^{2}$ tests due to small cell sizes. Statistically significant values at $p<.05$ are indicated by an asterisk. 
Table S5

Specific Mental Health Difficulties among Students and Faculty with Any Mental Health Difficulties

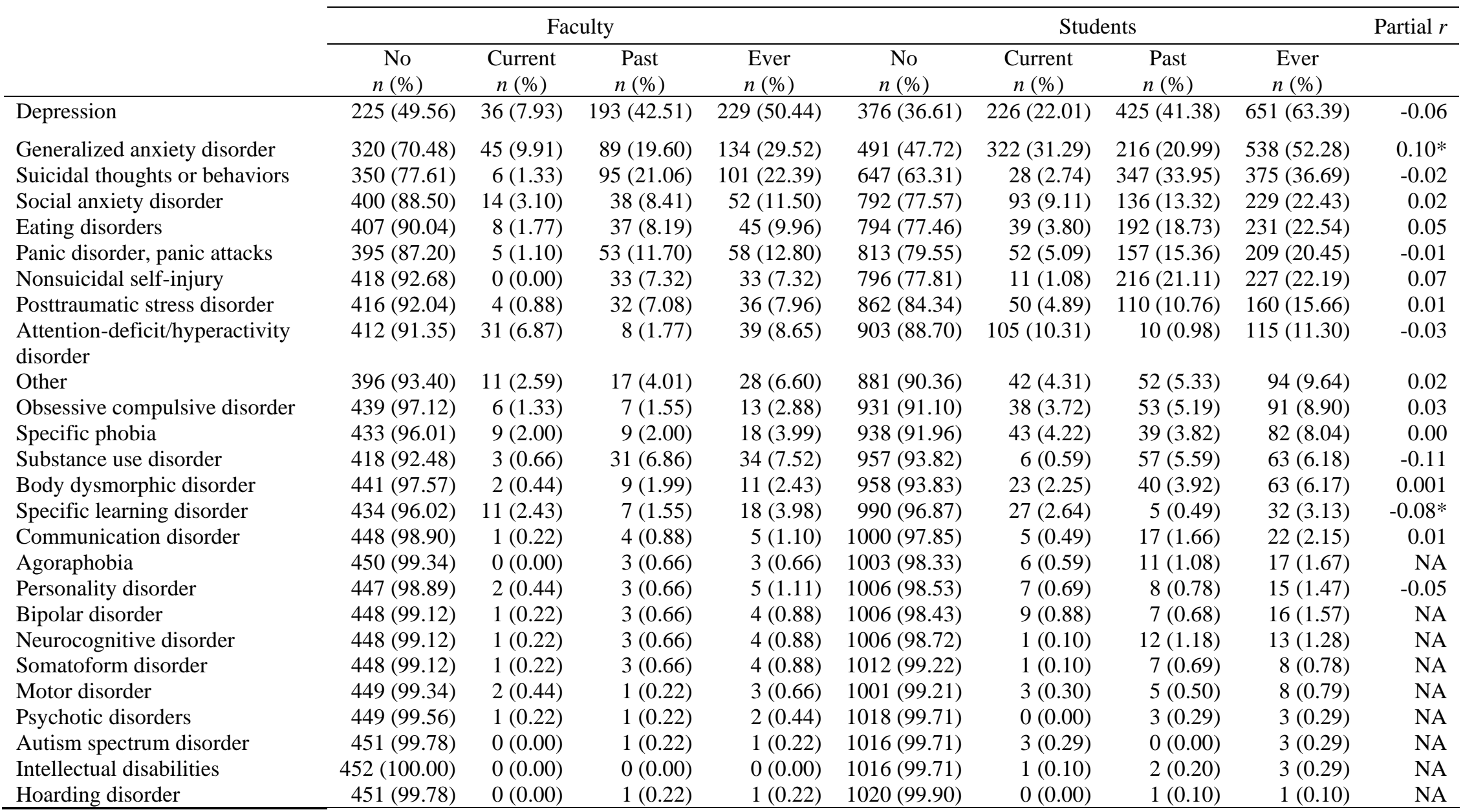

Note. The "ever" column reflects the sum of individuals who endorsed experiencing a specific mental health difficulties either

currently or in the past. For details regarding the specific phrasing of the above items, see the survey instrument on Open Science 
Framework (link in text). Partial $r$ values reflect a partial phi coefficient (correlation between two binary variables, student/faculty group status and "ever" mental health difficulty yes/no) controlling for number of total diagnoses. "NA" reflects statistical tests not conducted due to small cell sizes. Statistically significant values at $p<.01$, adjusted for multiple comparisons, are indicated by an asterisk. 